\title{
La lección de anatomía del doctor Nicolaes Tulp: el comienzo de una utopía médica
}

\author{
ROBERTO ROSLER ${ }^{1}$, PABLO YOUNG ${ }^{2}$
}

\section{The Anatomy Lesson of Dr. Nicolaes Tulp: The beginning of a medical utopia}

The Anatomy Lesson of Dr. Nicolaes Tulp was painted by Rembrandt Harmenszoon van Rijn at the early age of 26 years. In the XVII century these paintings were very popular in the Netherlands, and in this country the cities flourished as cultural centers searching the anatomy knowledge. Nicolaes Tulp was one of the persons in the center of Amsterdam's scene during XVII century. In 1632 Tulp was 39 years old, and he was an anatomist and a surgeon. Rembrandt masterly shows an autopsy performed by Dr. Tulp. This picture is the description of the beginning of a medical intellectual utopia: the absolute visibility of the disease. Unfortunately this utopia is blind to the complete visibility of the psycho-socio-cultural dimensions of the ill.

(Rev Med Chile 2011; 139: 535-541).

Key words: Anatomy; Portraits; History of medicine.

\section{Rembrandt el pintor y los retratos}

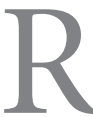

embrandt Harmenszoon van Rijn pintó este cuadro (Figura 1) a la temprana edad de 26 años. Nació el 15 de julio de 1606 en Leyden, una de las "cunas" de la educación médica. Fue a la universidad pero rápidamente se aburrió y solicitó a sus padres abandonarla para dirigirse a Amsterdam y dedicarse al estudio de la pintura. En 1631 se casó con Saskia van Uylenburgh, que era la prima de uno de los vendedores de arte más exitosos de Amsterdam. Este matrimonio le proporcionó importantes conexiones sociales para conseguir pedidos de retratos y pinturas de la alta sociedad holandesa. Es justamente su cuñado quien lo recomienda a Nicolaes Tulp, quien deseaba encargar un retrato grupal ${ }^{1}$.

En el siglo XVII estos tipos de retrato eran muy populares en las Provincias Unidas o Países Bajos, y se habían convertido en una verdadera institución social. El retrato grupal se transformó en el símbolo de una clase media que ascendía social y económicamente. Además era socialmente bien visto aparecer en compañía de gente poderosa. Por este motivo, ¡muchas personas pagaban para aparecer en estos retratos! Para comprender esto hay que entender que salir en estos retratos era como salir en la actualidad (anacronismo mediante) en la tapa de una revista de novedades sobre el ambiente artístico ${ }^{2}$. Esto convertía a este tipo de cuadros en una difícil tarea para los pintores ya que debían cumplir con las pretensiones de todos los participantes que habían pagado y que querían estar ubicados en un lugar de privilegio.

\section{Contexto histórico}

Amsterdam pertenecía a las Provincias Unidas cuya religión era el Calvinismo y que venía de lograr su independencia de España luego de treinta años de guerra. Dicha independencia les permitió ganar el derecho a comerciar libremente. Las Provincias Unidas tuvieron un golpe de suerte, 


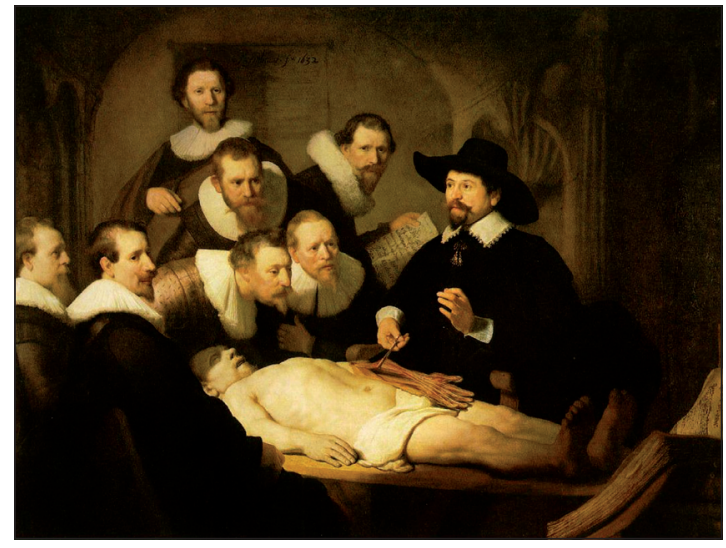

Figura 1. "La Lección de Anatomía del Doctor Tulp" de Rembrandt.

ya que su principal competidor comercial, Venecia, había sido destruido por la plaga al no querer ejecutar la cuarentena y el cordón sanitario para no entorpecer su comercio. Esta miopía le costó la muerte de un tercio de su población adulta y su desaparición como potencia marítima ${ }^{3}$.

Durante el siglo XVII el 50\% del comercio europeo era transportado en barcos holandeses. Las Provincias Unidas tenían puertos en el Océano Índico, Formosa, Japón, Java, las Indias Orientales y Occidentales, Guayana, Brasil y Nueva Amsterdam (la actual Nueva York) ${ }^{3}$.

\section{El arte y la religión}

Siguiendo su ascenso meteórico los burgueses de Amsterdam vivían bien y deseaban verlo reflejado en el arte.

El protestantismo fue desde su inicio iconoclástico, dándole la autoridad a la palabra sobre la imagen. Sin embargo, fue indulgente con el placer visual de sus clases altas, en especial si le era ideológicamente útil.

Nicolaes Tulp era una de las personas que ocupaba el centro de la escena en Amsterdam durante el siglo XVII ${ }^{4}$. En 1632 tenía 39 años. Tulp era un estudioso, un anatomista y un cirujano. Se había hecho famoso por un tratado sobre monstruos y por haber descubierto la válvula ileocecal. Pero, por sobre todo, Tulp era un "animal político". Fue ocho veces tesorero de la ciudad de Amsterdam.

En el siglo XVII las Provincias Unidas en general, y Ámsterdam en particular, florecieron como centros culturales en la búsqueda del conocimiento anatómico ${ }^{5}$. Esto no le generó conflictos con la Iglesia Calvinista. Recordemos que en esta misma época, Galileo Galilei, de no haberse retractado de sus afirmaciones, hubiera sido condenado por la Inquisición en Italia.

Mientras que en el sur de Europa la Iglesia no quiso ver por el telescopio de Galileo, en el norte de Europa se abrieron los ojos a los descubrimientos.

En 1668 Anton von Leeuwenhoek inventó el microscopio en las Provincias Unidas 6 . En 1664, en la Inglaterra protestante, Thomas Willis disecó cerebros y afirmó que el sistema nervioso es el asiento del alma ${ }^{7}$.

El mismo Descartes huyó de Francia y buscó refugio en Leyden, para poder tener libertad de pensamiento.

Estos hechos revelan un "matrimonio" entre revoluciones científicas y teológicas. ¿ $\mathrm{Si}$ Lutero se atrevió a desafiar a la Iglesia, cómo los médicos de la época no a iban a atreverse, luego de 1.500 años, a desafiar a Galeno? ${ }^{8}$

El 16 de enero de 1632 llegó la oportunidad para pintar el cuadro. Un reo, acababa de ser colgado por robo y con ello se logró la oportunidad de tener un cadáver para ser disecado.

En el siglo XVII, a diferencia del sur de Italia donde la muerte era un proceso súbito, en el norte de Europa la separación entre el cuerpo y el alma se veía como un proceso gradual. Los ajusticiados eran condenados a la disección porque precisamente la práctica anatómica se consideraba un castigo añadido sobre el cuerpo, todavía portador de una cierta identidad de la persona ${ }^{9}$. Vemos entonces que el criminal es la víctima de la justicia y de una triple violencia médica, corporal y espiritual.

En las lecciones de anatomía los cuerpos enanizados por una perspectiva despiadada, parecen muñecos descuartizados e inmolados ante un saber tan nuevo como inclemente. El médico no se siente interpelado por ningún deber especial de compasión ante ese cuerpo exánime que ya no tiene acceso a ninguna curación ${ }^{10}$.

\section{Análisis del cuadro}

El fondo en sombras es poco visible (Figura 1). Vemos dos libros. El que está colocado en el ángulo inferior derecho probablemente sea el "best seller" 
de anatomía del momento, "De humani corporis fabrica" de Andreas Vesalio (1543) ${ }^{11}$. El que tiene en sus manos el asistente que se encuentra a la derecha de Tulp se supone que es la lista de los presentes en la disección. La lección no es sólo para los observadores de la pintura. Tulp mira hacia la audiencia sentada en el anfiteatro rodeando la mesa de disección.

Para estudiar el estilo pictórico habitual de una lección de anatomía debemos analizar la "Lección de Anatomía del Doctor Sebastián Egbertsz" (Figura 2) pintada en 1619 por Thomas Keyzer ${ }^{12}$. En esta pintura la línea media está demarcada por el esqueleto y las figuras están ordenadas en dos triángulos perfectamente simétricos ${ }^{13}$. Esta pintura estaba en la mente de Rembrandt cuando pintó "su" "Lección de Anatomía del doctor Nicolaes Tulp", dispuesto a romper con esta uniformidad estática. El Profesor Tulp es la persona que controla el evento. Está a la derecha del cuadro dentro de una pirámide que culmina en su sombrero negro, símbolo de su alto status social. Son necesarios todos los observadores para contrabalancear la figura todopoderosa de Tulp ${ }^{14}$. El cadáver en el centro parece una cuña entre los cuerpos vivientes. Por esta composición los dos protagonistas principales de esta pintura son el doctor Tulp y el cadáver. En la pintura de Keyzer el esqueleto cumple sólo la función de agrupar los participantes de la disección, en cambio el cadáver en la obra de Rembrandt es el centro de la pintura y aumenta su dramatismo psicológico. En las pinturas de Rembrandt, las figuras suelen ser fuentes de luz con luminosidad

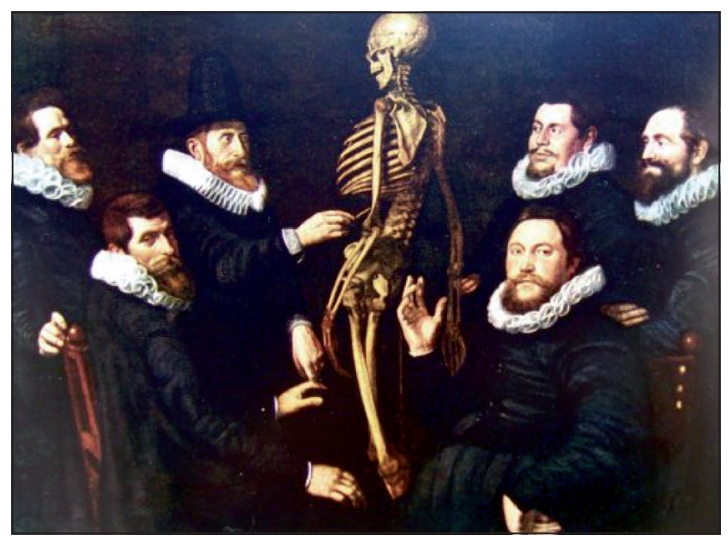

Figura 2. "Lección de Anatomía del Doctor Sebastián Egbertsz". intrínseca. En la lección de anatomía la luz proviene, paradójicamente, del cadáver ${ }^{15}$. Este doble contraste lumínico genera un "degradé" de vida (muerto-vivo, inferior-superior) y un "degradé" de poder psicológico (el que tiene el saber y los que no lo tienen, derecha-izquierda). Las posturas y las expresiones faciales de los atentos oyentes de Tulp se asemejan a aquellos que escuchan a Jesús.

El carácter litúrgico del anatomista como un sacerdote se repite en la segunda "Lección de Anatomía del doctor Joan Deyman de Rembrandt" (Figura 3), en la cual el cuerpo se parece al Cristo muerto del cuadro de Mantegna ${ }^{16,17}$. Temáticamente también existe una semejanza entre la ciencia y la religión. Ambas ofrecen una visión autoritaria de hechos "subterráneos" que están fuera del alcance de nuestra mirada.

La ciencia como religión es una tendencia que se transformó en ideológicamente prominente por primera vez en la Europa del siglo XVII y que ha llegado hasta nuestros días ${ }^{18}$. La medicina en esta nueva época conjugaba la teoría y la práctica.

En el cuadro vemos plasmada la aceptación del doctor Tulp de que el conocimiento se basa en la necesidad de la confirmación empírica a través del hecho de que el profesor está dando una clase y simultáneamente disecando sin la necesidad de leer ningún libro ${ }^{19}$.

Por el contrario, las lecciones de anatomía medievales (Figura 4), bajo el influjo de la sabiduría de Aristóteles y Galeno, separaban ambas funciones ${ }^{20}$. El médico se distanciaba del "trabajo sucio" de la disección, que se dejaba en manos de

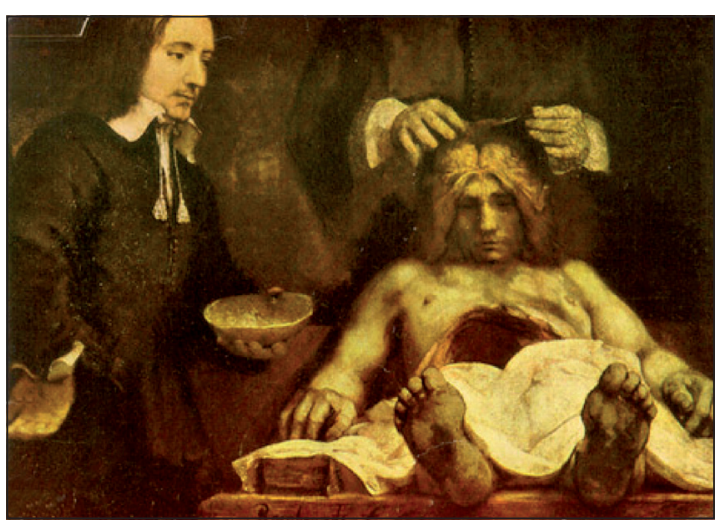

Figura 3. "La Lección de Anatomía del Doctor Joan Deyman" de Rembrandt. 
un cirujano-barbero, mientras que el profesor se concentraba en la lectura del texto de Galeno. Si se descubrían discrepancias entre el dogma anatómico galénico y el cadáver, se zanjaban como un defecto, o una "broma", de la naturaleza.

Las lecciones de anatomía (Figura 4) eran eventos tanto científicos como políticos, presenciados no solamente por estudiantes de medicina y académicos sino también por prominentes representantes de la vida política de la ciudad ${ }^{21}$. El teatro anatómico estaba centrado en la tabla de disección y alrededor de ella había círculos concéntricos de asientos, en los cuales los visitantes estaban asignados según su rango social y no tan sólo su conocimiento científico. Lo que vemos aquí es una nueva forma de mostrarse, de mirar, de verse y de ser visto. El agente de esta nueva forma de mirar es la ciencia en si misma ${ }^{22}$. Los espectadores estaban dispuestos a pagar más por ver una mujer desnuda, podemos inferir que estas, en teoría, disecciones anatómicas, eran en realidad actos de voyeurismo ${ }^{23}$.

Entregado a la mirada implacable de doctos y discípulos, y también a la de un público que no ocultaba su afán voyeurista de sensaciones morbosas, el cadáver (palabra cuya raíz latina es cadere, caer) descendía desde su condición de ciudadano digno, protegido por honores y mortajas en su destino de viajero a un mundo espiritual supe-

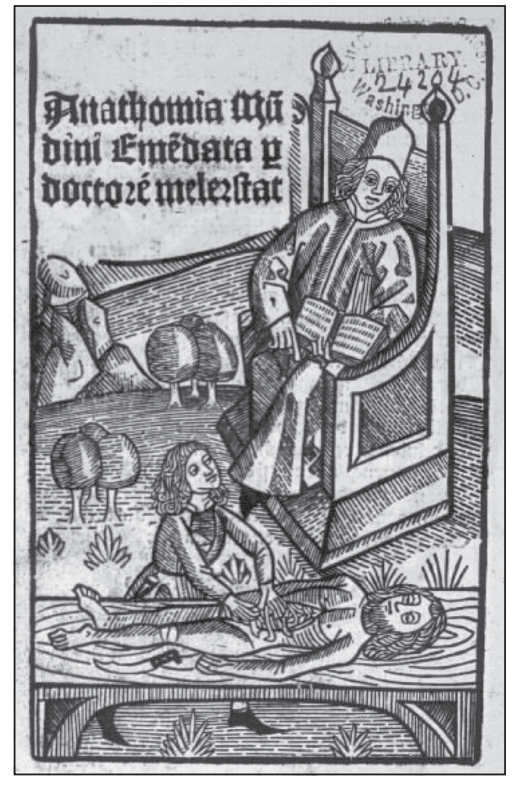

Figura 4. Lección de Anatomía de la escuela italiana (siglo $\mathrm{XV}$ ). Autor anónimo. rior, a un simple y burdo instrumento didáctico y señal clara del camino de las enfermedades que lo habían devastado.

Los cuadros de Rembrandt traducen con exactitud esa mezcla de horror y fascinación que hubo de envolver las primeras lecciones de anatomía ${ }^{24}$. Un ejemplo de esto es que Luis XIV encargó a su cirujano personal (Pierre Dionis) que realizara lecciones de anatomía en el Jardín del Rey en Versailles. Este espectáculo que estaba de moda, se transformó en un éxito arrollador, debieron dar invitaciones numeradas para una multitud de burgueses elegantes que, de toda Europa, venían a ver las disecciones ${ }^{25}$. Simultáneamente Molière ironizaba en "El Enfermo imaginario"26: "Están aquellos que le dan una comedia a sus amantes, pero darle una disección es algo mucho más galante". Sugiriendo así que los motivos de Luis XIV no eran en realidad "científicos".

No todos en la pintura "ven" lo mismo ${ }^{27}$. Un participante dirige su mirada hacia el texto de anatomía para verificar si lo que el doctor Tulp está diciendo es correcto. Otro mira hacia los observadores de la pintura y dirige nuestra atención hacia la disección anatómica.

La pintura expresa un combate latente: la fascinación e interés de los observadores pero también su miedo, ansiedad e incomodidad al descubrir los misterios del cuerpo. Hecho comprensible ya que sólo dos de los siete participantes eran médicos. Sin embargo, sentimos que preside una mirada unificada, la del triunfo de la ciencia sobre la muerte.

Esta pintura no es una lección de anatomía común ${ }^{28}$. Habitualmente se comenzaban las disecciones por las vísceras abdominales, ya que eran las que más rápidamente se descomponían. A continuación se disecaban el tórax y la caja craneana, quedando para el final las extremidades. En la segunda Lección de Anatomía de Rembrandt (Figura 3) podemos observar este orden de disección ${ }^{29}$. Pero en este cuadro vemos al doctor Tulp comenzando la disección por el miembro superior izquierdo. Evidentemente Tulp quería mostrar algo en especial sin pasar por todos los pasos de una disección habitual. Tulp está señalando un músculo (el flexor digitorum superficialis) con un fórceps ${ }^{30}$. Esto es inusual ya que habitualmente se utilizaban punteros para señalar las estructuras anatómicas (Figura 5). La utilización del fórceps significa que el doctor Tulp no está mostrando una estructura sino una función. Su mano izquierda 


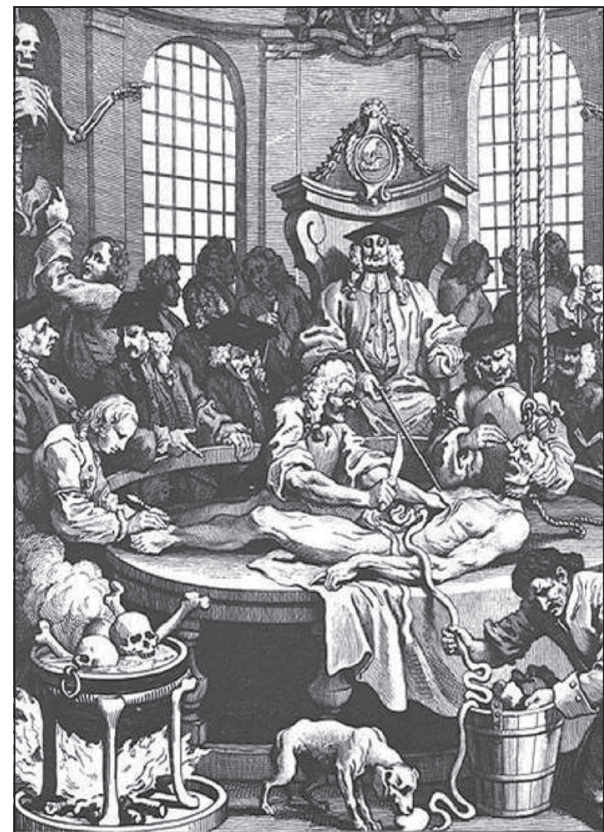

Figura 5. Utilización de puntero. Grabado en madera de una disección anatómica del siglo XVII, autor anónimo.

está sostenida en una forma extraña, seguramente mostrando la acción del músculo señalado.

Por lo tanto, la pintura describe dos acciones que están sucediendo en paralelo: Tulp muestra con el fórceps la acción del músculo en el cadáver mientras que con su mano izquierda muestra la acción del músculo "in vivo". Este hecho se refuerza porque mientras un asistente mira hacia el antebrazo del cadáver, el otro mira hacia a la mano izquierda del doctor Tulp ${ }^{31}$. No estamos presenciando una lección de anatomía estática, sino una de anatomía funcional ${ }^{32}$. Esto muestra una cualidad esencial de las pinturas de Rembrandt que es el movimiento. La preocupación de Rembrandt por el movimiento también hace que esta pintura personifique el pensamiento europeo del siglo XVII: el movimiento era central en las ideas de Descartes, Gassendi, Galileo, Leibniz y Newton.

Un tema de debate es la inserción del flexor digitorum superficialis que en el cuadro tiene como origen el epicóndilo lateral del húmero cuando sus inserciones reales son el epicóndilo medial del húmero, la apófisis coronoides del cúbito y la diáfisis del radio.

En 2006, relacionado con la celebración del
400 aniversario del nacimiento de Rembrandt, un equipo de especialistas disecó un miembro superior para confirmar si existían errores anatómicos en la pintura de Rembrandt. Luego de dicha disección confirmaron algunos errores menores y la inexactitud de la inserción del flexor digitorum superficialis $^{30}$. Sin embargo, diferentes autores se resisten a aceptar que Rembrandt haya pintado esta anomalía por error.

De Lint ${ }^{33}$ afirma que Rembrandt, un buen anatomista, expresamente tergiversó el origen de este músculo para darle un mayor equilibrio artístico a la pintura. No sin justificación Hove y col. ${ }^{34}$ afirman que el doctor Tulp, famoso anatomista, al ver la pintura debió reconocer el error y aceptarlo por algún motivo sino jamás le hubiera permitido retratar la anatomía en forma incorrecta. Heckscher sugiere que Rembrandt malinterpretó una imagen de Vesalio confundiendo la anatomía del brazo derecho con la del brazo izquierdo ${ }^{35}$. Finalmente, varias de las observaciones realizadas por el equipo de especialistas de miembro superior han sido refutadas ${ }^{30,36}$.

Rembrandt falleció en Amsterdam el 4 de octubre de 1669. Se lo considera uno de los mayores maestros barrocos de la pintura y el grabado, siendo con seguridad el artista más importante de la historia de las Provincias Unidas. Habiendo alcanzado el éxito en la juventud, sus últimos años estuvieron marcados por la tragedia personal y la ruina económica. Entre los mayores logros creativos de Rembrandt están los magistrales retratos que realizó para sus contemporáneos, sus autorretratos y sus ilustraciones de escenas bíblicas.

Para finalizar podemos decir que este cuadro es la descripción del inicio de una utopía intelectual médica: la de la completa visibilidad de la enfermedad ${ }^{37}$.

Foucault afirma en su provocativo capítulo "Abrid algunos cadáveres" ${ }^{37}$ que la lección de anatomía será la plataforma que posibilitará a Xavier Bichat (1771-1802), un siglo más tarde, el desarrollo de esas dos formas de saber yuxtapuestas que son la anatomía patológica y la clínica basado en un principio de desciframiento del espacio corporal. Al igual que en la pintura es el ojo de Bichat (su "ojo clínico") el que le otorga un principio epistemológico absoluto para el análisis anátomo-patológico.

Con la constitución del saber anatómico (retratado por Rembrandt) nace una diferencia 
implícita dentro de la episteme occidental entre el hombre y su cuerpo. Allí se encuentra el origen del dualismo contemporáneo que, como afirma David le Breton ${ }^{38}$, "le otorga al cuerpo el privilegio de ser interrogado científicamente por el médico con preguntas especificas con indiferencia de cualquier otra referencia" (el alma, la sociedad, las emociones, los afectos y un largo etcétera $)^{38}$.

El resultado de esto es la mayor contradicción de toda medicina que no se ocupa de la persona: ¿Quién está enfermo, el hombre o alguna víscera? ¿A quién hay que curar, al enfermo o a la enfermedad?

Los impactantes avances en biología molecular, genética y neuro-imágenes son las causas de la génesis de un renacimiento de la idea de encontrar en el cuerpo humano los secretos del hacer humano ${ }^{39}$.

Es interesante recordar que desde el punto de vista lexical quienes ejercían la curación entre los griegos eran equiparados con aquellos fieles servidores guiados por el afecto hacia la persona. A este grupo se vincula el verbo therapeuo (servir).

Therapeuo designa al encargado de cuidar al enfermo como servidor. Si therapeutés pudo llegar a designar al médico fue porque en su raíz estaba la de "encargado de cuidar" y esta noción de cuidar consistía la esencia del servir. En therapeuo las confluencias de sentido son evidentes ya que significa tener cuidado de, tener solicitud por, servir, prestar cuidados médicos ${ }^{40}$.

La raíz med (medicar, médico, medicamento) puede definirse como medida, no de medición sino de moderación, apta para reinstaurar el orden en un organismo enfermo ${ }^{40}$.

El hombre que "sabe los medea", no es un pensador, sino uno de los moderadores que sabe tomar las medidas que necesariamente se imponen. Medeor, del latín, significa tratar una enfermedad según las reglas. La noción no es hacer recobrar la salud a un enfermo sino someter a un organismo alterado a las reglas.

Las distintas palabras que en las lenguas indoeuropeas representaban el verbo curar llevaban exclusivamente un complemento de persona, no se curaba algo sino que se curaba a alguien.

El latín medeor representa un cambio ya que el objeto de atención del médico ya no es el paciente sino la enfermedad, que se presenta ante sus ojos junto con el conjunto de reglas para tratarla. La relación ya no es médico-paciente sino médicoenfermedad.
Desde la antigüedad, hablando de medicar y de médicos, alternan dos conceptos: ¿el punto de partida es el enfermo o la enfermedad?

En el primer caso, el médico es la persona que cuida, que cura, que se pre-ocupa por el bienestar de quien está a su cuidado, en el segundo es el especialista que arregla desperfectos orgánicos.

Lamentablemente la utopía de la completa visibilidad de la enfermedad suele ser ciega a la completa visibilidad de las dimensiones psico-socio-culturales de los enfermos y está sesgada hacia el especialista que arregla desperfectos orgánicos porque predomina el Medeor sobre el Therapeno. Por este motivo creemos que la medicina positivista comienza en los siglos XVI y XVII, con su bagaje de conocimientos anatómicos, su lento alejamiento de la mirada propuesta por Platón en "El Banquete": "Me atrevo a asegurar que el amor preside a la medicina" 39 .

\section{Referencias}

1. Rosenberg J. Rembrandt, life and work. Cornell University Press editors, Ithaca, New York, USA; 1980.

2. Mccall GH. Paintings By The Great Dutch Masters Of The Seventeenth Century. Kessinger Publishing Co editors, London, UK; 2005.

3. Praak M. The Dutch Republic in the seventeenth century: the golden age. University Press editors, Cambridge, UK; 2005.

4. Simpson D. Nicolaes Tulp and the golden age of the Dutch Republic. ANZ J Surg 2007; 77: 1095-101.

5. Burke P. Formas de historia cultural. Alianza editores, Madrid, España; 2000.

6. Miranda CM. [Johannes Vermeer and Anthon van Leeuwenhoek: Delft Art and Science together during the golden Dutch century] Rev Med Chile 2009; 137: 567-74.

7. Zimmer C. Soul Made Flesh: The Discovery of the Brainand How it Changed the World. Free Press editors, New York, USA; 2004.

8. Porter R. The Greatest Benefit to Mankind. A medical history of humanity from antiquity to the present. Fontana editors, London, UK; 1997.

9. Ariés P. Morir en occidente. Adriana Hidalgo editora, Villa Ballester, Argentina; 2000.

10. Porzecanski T. El cuerpo y sus espejos. Estudios antropológico-culturales. Planeta editores, Montevideo, Uruguay; 2008.

11. Fenster J. Mavericks, miracles and medicine. Barnes and 
Noble Books editors, New York, USA; 2005.

12. Zuffi S. One thousand years of painting. Electa editors, Milán, Italia; 2004.

13. Loudon I. Western Medicine. An illustrated history. Oxford University Press editors, New York, USA; 1997.

14. IJpma FF, van de Graaf RC, Meek MF, Nicolai JP, van Gulik TM. The anatomy lesson of Dr. Nicolaes Tulp painted by Rembrandt in 1632. ANZ J Surg 2008; 78: 1059-61.

15. Leperchey F. Apropos of the "Lesson in anatomy". Morphologie 2000; 84: 5-12.

16. Barutta J, Rosler R. Los enfermos y los métodos de la medicina: sus historias. Punto y Coma editores, Buenos Aires; 2010.

17. Haas LF. The Anatomy Lesson of Dr Joan Deyman, by Rembrandt (1606-69). J Neurol Neurosurg Psychiatry 1992; 55: 908.

18. Sendrail M. Historia Cultural de la enfermedad. EspasaCalpe editores, Madrid, España; 1983.

19. Kopelman LM, De Ville KA. Rembrandt's anatomy lesson as a metaphor for education. Curr Surg 2003; 60: 150-1.

20. Le Goff J, Truong N. Una historia del cuerpo en la Edad Media. Paidós editores, Buenos Aires; 2005.

21. Kruger L. The Scientific Impact of Dr. N. Tulp, Portrayed in Rembrandt's “Anatomy Lesson". J Hist Neurosci 2005; 14: 85-92.

22. Baljet B. The painted Amsterdam anatomy lessons: anatomy performances in dissecting rooms? Ann Anat 2000; 182: 3-11.

23. Mathiasen H, Mag C. Vile bodies: the anatomy lesson of Dr. Tulp. Am J Med 2010; 123: 476-7.

24. Anz T, Araujo K, Armus D, Horisch J, KarpensteinEbbach C, Morillo J, et al. Literatura, cultura y enfermedad. Paidós editores, Buenos Aires; 2006.

25. Barcat JA. [Anatomy lessons]. Medicina (B Aires) 2000; 60: 146-8.
26. Molière. El enfermo imaginario, $17^{\mathrm{va}}$ ed. Biblioteca EDAF editores, Madrid, España; 1985.

27. Bankl HC, Bankl H. Dr. Nicolaas Tulp. A critical view of Rembrandt's Anatomy Lesson. Wien Klin Wochenschr 2000; 112: 368-71.

28. Afek A, Friedman T, Kugel C, Barshack I, Lurie DJ. Dr. Tulp's Anatomy Lesson by Rembrandt: the third day hypothesis. Isr Med Assoc J 2009; 11: 389-92.

29. Lakke JP. Autopsy practises for brain dissections and Rembrandt's anatomy lesson of Dr. Deyman. J Hist Neurosci 1998; 7: 101-7.

30. IJpma FF, van de Graaf RC, Nicolai JP, Meek MF. The anatomy lesson of Dr. Nicolaes Tulp by Rembrandt (1632): a comparison of the painting with a dissected left forearm of a Dutch male cadaver. J Hand Surg Am 2006; 31: 882-91.

31. Hagen RM, Hagen R. Los secretos de las obras de arte. Taschen editores, Colonia, Alemania; 2005.

32. Masquelet AC. The anatomy lesson of Dr Tulp. J Hand Surg Br 2005; 30: 379-81.

33. De Lint JG. Rembrandt. Kruseman, The Hague; 1933.

34. Hove LM, Young S, Schrama JC. Dr Nicolaes Tulp's anatomy lecture. Tidsskr Nor Legeforen 2008; 128: 716-9.

35. Heckscher WS. Rembrandt's Anatomy Lesson of Dr. Nicolaes Tulp, New York University Press, New York; 1958.

36. Jackowe DJ, Moore MK, Bruner AE, et al. New insight into the enigmatic white cord in Rembrandt's The anatomy lesson of Dr. Nicolaes Tulp (1632). J Hand Surg Am 2007; 32: 1471-6.

37. Foucault M. El nacimiento de la clínica. Una arqueología de la mirada médica, $12^{\mathrm{da}}$ ed. Siglo XXI editores, México D.F; 1987.

38. Le Breton D. Antropología del cuerpo y modernidad. Ediciones Nueva Visión, Buenos Aires; 1995.

39. Vallejo G, Miranda M. Políticas del cuerpo. Siglo XXI editores, Buenos Aires; 2007.

40. Bordelois I. A la escucha del cuerpo. Puentes entre la salud y las palabras. Libros del Zorzal, Buenos Aires; 2009. 